DE DE GRUYTER OPEN
Research Article

(C) 2017 Dominador L. Pagliawan. This is an open access article licensed under the Creative Commons Attribution-NonCommercial-NoDerivs License (http://creativecommons.org/licenses/by-nc-nd/3.0/).

\title{
Feature Style for Academic and Scholarly Writing
}

\author{
Dominador L. Pagliawan
}

DA LitCom, Leyte Normal University Tacloban City, Philippines

Doi: 10.1515/ajis-2017-0004

\begin{abstract}
Writing research and other academic papers considered to be technical requires formal style and usage of a language. Moreover, it demands a serious tone and, as such, it does not allow jokes, expressions, and creative or artistic nuances contrary to informal essays and feature articles. Far from being entertaining, then, technical papers, to include research works, have been branded as something boring to read, hence their limited readership in contrast, again, to feature-penned reading materials. Rather than reject an academic paper submission of a college student sampling a deviant style, or feature in particular, this inquiry made use of his paper as an instrument for a case study. Using a qualitative, textual analysis method, this study examined his work in view of feature writing techniques to determine the extent of its departure from formal style, and to weigh its entertainment value that could arouse interest and promote ease of reading. The results indicate a breakthrough in academic paper writing which could make research-based articles more entertaining to read.
\end{abstract}

Keywords: Feature writing, academic writing, scholarly writing, formal writing, writing style

\section{Background of the Study}

In a Literary Criticism class that I recently handled, I required the students to submit, for the term's output, a literary critique using a critical theory of their choice, a close reading technique, or a textbased stand/claim that they could prove in their analysis. To ensure zero plagiarism given the rampant copy-pasting activities with the Internet nowadays, I did not allow them to use those popular texts authored by national and international literary figures. Instead, I had them choose those that were penned by local but published writers, knowing that the latter's works still lack critical appraisals available in the net for one to copy-paste.

Since I happened to be one of the local writers writing in our native language, it was therefore expected that some of the students would choose my works. True enough, one of them in the person of JR Jaham Mel Teombe Lumbre Macaso opted to critique one of my short stories. When I checked their individual outputs, his paper caught my attention-it was written in feature style, not in the way scholarly papers are penned. Detection was quick on my part, having been a school paper adviser for so many years, being a frequently-invited judge in journalistic writing competitions, and as a print media practitioner myself. In fact, one of my published books is a "howto' on feature writing and creative non-fiction.

My immediate reaction at seeing his paper was to give it a failing grade. But I hesitated, more so when I noticed that he had sound arguments and claims that made sense. The only problem was his manner of writing, which contradicted the standard of writing technical papers. Plagued with second thoughts, I then tried to consider his work as I could see a glimpse of light from it. For though he unconsciously deviated from the convention, he seemed to be pioneering a breakthrough that could revolutionize the way academic papers are written. I was seeing it myself, so instead of 
penalizing his paper, I gave it the highest grade, with high hopes for its promise.

This paper therefore investigated the possibility and wisdom of writing scholarly papers with the use of feature style. It is explained by the fact that, for reasons of intense seriousness, such papers are indeed boring to read, hence their fewer readers. They lag behind in terms of readership compared to commercial entertainment magazines catering to feature articles. Perhaps it's high time academic papers are also penned in a creative, feature manner, knowing that readers are also after pleasure.

\section{Linguistic Demands of Academic Writing}

Academic writing could be synonymous with research writing, scientific writing, technical writing, and scholarly writing in that, all of them demand an exact language, complete sentences, well developed prose, organized and comprehensive work (Roberts, 2003). It is a highly mechanical form of writing, dwelling only on facts, and is not influenced by human emotions.

These types of writing, as hinted by Hyland (2004), come in various forms and genres existing across disciplines. They comprise a lot of critical approaches for application in writing about a subject. But what's too obvious about them is that, they are written impersonally based on highly investigated information. They are meant to support or argue a concept, and do away with emotions, bias, speculations, and humor. Most noticeably, they use a formal language and a very serious tone, giving no place for grammatical flaws, as well as for artistic or creative expressions. As a form of scholarly writing, they are preoccupied with an objective stand, adequately organized details, a clearly developed topic, and a formal academic discourse.

Academic writers then inevitably face these conventions to follow, particularly the demand for formal language use. Some writers, however, are open to changes while maintaining selected conventions. Pennycook (1997), along with other writers, agreed to challenge these entire writing traditions. They are for the idea that something new, albeit deviant from old styles, be introduced as writing alternatives to challenge, for instance, the strict adherence to language formality in academic papers.

Indeed, in some academic circles, these conventions are no longer religiously followed. We could notice that, sometimes, authors of academic articles use personal pronouns to refer to themselves (Fowler, 1991) when in fact, as convention has it, such write-ups must accordingly be impersonal. The supposed need to challenge those conventions (Ivanic, 1998) is now seemingly at work. As to what extent new writing styles could apply is still a subject for debate. For sure, no new limits have already been drawn. Academic writers can still experiment on this, mostly consciously or at will. But for a student in a remote region of the world to write one academic paper that exemplifies an unconscious deviation from formal language use, or out of ignorance, is indeed worth investigating.

\section{Attributes of Feature Article}

Well-crafted feature articles differ from scholarly papers in many aspects: in terms of style, tone, language use, and organization. They are opposite to each other. What's being disallowed in academic writing, it seems, are technically welcome in feature writing. While the former espouses a straightforward pace, the latter takes a leisurely movement in reaching its destination (Harcup, 2009), painting a vivid scenery, enhanced characterization, elaborate actions, and realistic local color, all with the paint-brush of description.

Along the way, features may dwell on serious matters (Boyd, 2001); but most of the time, they employ the lighter touch, the entertainment technique. Devices such as confessional mode, or the presence of the author in the write-up come into play, proliferating particularly in journalism since the '90s (Dovey, 2000). This "I" in a confession prose presents the information through the writer's voice, akin to personal essay, making the experiences and insights more believable. Of course the dictum 'show, don't tell,' is very much at work. It informs the difference between simply hearing about a thing, and seeing it in detail. To further entertain the readers, quotes from the exact lines of people involved are given to make an episode come alive, with dramatic impact. 
From the title, which catches the eye, to the lead of the feature article, the element of interest is unleashed. After the title succeeds in hooking the reader, the introduction makes him desire to read on (Boyd 2001). A good feature, then, makes the reader laugh, cry, excited, annoyed, and many more, depending on the writer's intent. The language used is simple, the tone is conversational, and the flow is engaging, which means that the reader cannot help but participate and interact with the text. Furthermore, the style could be poetic, imaginative, and even humorous, all shown with sufficient embellishments.

In the end, the reader is rewarded (Harcup, 2009). There is such a thing as a 'pay off' that the feature writer gives as a token of gratitude to the reader who spent time and effort with the text. It is not monetary or in kind, of course; it's a sense of completeness and contentment on the reader's part. He parts from the text as a new person, renewed inside out, different from what he used to be. The experience in the text changes him, for it does not only enter his head-it invades his heart.

\section{The Critiqued Story}

My story that this student had critiqued is titled, Tipa-Manila which means, bound for Manila, in English. This was written originally in Waray, my native language spoken in the islands of Leyte, Samar, and Biliran, which comprise the Eastern Visayas region of the Philippines. The story is set during that time when the only means of transportation from this region all the way to Manila and vice versa was by sea. The ship from Tacloban would pass by Catbalogan before proceeding up north to the big city.

The story's main characters, Man Caloy and Mana Bising, are from Samar who were going to Manila with Catbalogan as their boarding point. They were an old couple, or peasant farmers, living in a remote place of Samar island. Both of them were illiterates who lived all to themselves in their small house near their farm. Their children who lived elsewhere already had their own families, the eldest being based in Tondo, Manila. At the moment, all that they had was a cute, little piglet that they loved and cared for like a human baby-part of their family.

One time, their son in Manila sent them a letter inviting them to vacation in the country's capital for a few weeks. The chance made the couple so excited as the they could now visit the big city for the first time. Short of anything to bring as present to their son there, they brought with them their beloved piglet when their day of departure came. They went to the town of Catbalogan in order to wait for the ship that was coming from Tacloban. Since it was December, a passenger season, too many people were there at the pier waiting for the boat's arrival.

The big crowd forced their way up the ship when it came, only to be greeted by the bigger bulk of passengers inside. Congested, the boat had no more place to offer for the new passengers who had to occupy the lobbies and corners just to be accommodated. As the couple squeezed their way here and there, the piglet struggled to free itself from Man Caloy's arms. With its body pressed every now and then, the piglet suddenly released its waste, causing the old man to let go of it till it ran everywhere. The couple could not help but chase it, to the great annoyance and anger of the heavily disturbed passengers.

The worst thing came when the piglet was able to trace the way down the ship and on to the pier. It ran all the way to the squatter area, under the makeshift houses where dirt and mud had settled. The couple still chased the animal. When they got it and finally returned to the ship, the vessel was already several meters away from where it docked. They shouted and shouted for it to come back, but it never did. Furious, Man Caloy beat the piglet almost to death under the heavy downpour. But Mana Bising still brought it with them when they left the port area.

They spent the stormy night at the town plaza with the dying piglet. Early in the morning, when they went to the jeep terminal, they heard some news that the boat that left for Manila had capsized at sea, and no survivors could be found. At hearing it, Man Caloy tenderly and lovingly picked up the piglet and tried to feed it with biscuits. But the piglet unconsciously refused to eat, ready to take its last breath. 


\section{How it was done}

Reliant on verbal data, this qualitative paper samples a critical instance case study focusing on document analysis. Interview of the student writer was also conducted to draw some insights that could shed further light on his work. Observation also played its role, particularly during the interview, and that time when I was browsing the outputs of his classmates to determine if others also used the same style, which yielded none.

With the student's paper in hand, I first read it a number of times, paying attention to its content, tone, organization, style, and language use, having the nature of academic writing and feature writing in mind. Then I marked down the words, phrases, sentences, and paragraphs that are heavy with the feature's qualities. The process of analysis followed, explaining why a passage passes for a feature work, and hinting at how it could have been written were it penned as a typical academic discourse. Lines that exemplify feature writing were cited to determine, for one, if they serve the purpose effectively, or better, compared to the conventional mode of writing academic papers. The main objective is not necessarily to prove if such papers can be written using feature style because, for sure, they can be. Rather, the major aim is to determine if writing them so is wiser.

That the source of data is limited to just one paper is explained by the fact that, in qualitative inquiries, such sources need not be numerous. Besides, that lone output is one-in-a-million since majority, if not all students asked to write a scholarly paper will not resort to writing it in feature style unless told to do so. That this source material was written by a student, and not by a professional, could be justified by the idea that, had it come from an informed, professional writer, the output would have been unnatural, conscious, and mechanical, unlike that of the concerned student's work. It was important that this work is original, fresh, and authentic so as to avoid artificial inputs that might impair the study's target.

The analysis proper treated the verbal data descriptively, gauging them against the common characteristics of feature articles, with the end view of proving that the text, indeed, uses the feature style, and attesting further that academic writing, after all, can be penned with the use of feature writing techniques.

\section{Results and Discussion}

In subjecting the student's work to critical analysis, some observable attributes embedded in it had emerged. They are then identified in the discussion that follows.

\subsection{A catchy title}

The title of the student's paper was UNEARTHING MARXISM FROM DOMS PAGLIAWAN'S TIPAMANILA. It is a brief but catchy title, no doubt, one that could easily hook the readers' attention into the text. As such, it satisfies the demand for what titles of feature articles should be. For while it looks quite academic, like a typical title for a literary critique, it is also expressively creative, largely because of the word 'unearthing' whose function in the title is not something literal, contrary to its common usage.

Usually, we literally unearth something that is buried in the soil, or that is hidden underneath a pile of things. That's the normal thing to do that is then captured easily by quantitative form of writing. But if we do that same action using that very word in locating abstract ideas from equally abstract meanings, then such unearthing must be something figurative, hence creative. Thus, it could be a deviation from empirical discourses that prohibits the figurative use of words and ideas, albeit in a title, knowing that the latter covers an entire study in capsule form.

Despite the choice and usage of that word in a figurative manner, hence its departure from precise literal expression, it doubtless serves its purpose. In fact, it sounds more emphatic, poignant in suggesting something should be pulled out. It activates imagination of something being drawn forcibly from a source where it used to be embedded. The action suggested is likewise vivid; yet, in the real sense of the word, it is simply about proving, in a critical analysis, that Marxism 
exists in the story, Tipa-Manila, thanks to the feature style of assigning a creative title to a written work.

\subsection{Personal point of view}

Academic papers, to include all types of research papers, always require a formal, written language. One way to do that is to strictly observe an impersonal presentation of ideas, which means that the author must be absent from the text and should avoid referring to himself/herself using personal pronouns such as "I," "me," or "mine." In lieu of these, words like "the researcher," "the writer," and "the author" could be used.

In feature articles, these personal pronouns are allowed, especially if the author is narrating a personal experience, or featuring a place or event that he/she personally witnessed. The student's work under study did just that-make use of personal pronouns in the text, as sampled by the following lines:

Marx says that literature is directly connected to real life, and he says he can prove it. And in this paper I will try to prove that Tipa-Manila - with Marx's help - is connected to our real lives.

Based on this paper I conclude that the powerful driving force of the story Tipa-Manila is the constant struggle of the couple-Caloy and Bising — to survive the kablas' life.

Had this been a paper written as a typical scholarly work, the pronoun "l" here would not have been used in the first place, nor would it be tolerated by the teacher, or whoever would edit the text. But with feature for a style, the student-writer freely used it, with impact, the conclusion being more believable and authentic, heightened by a sense of responsibility from the writer's own confession.

\subsection{Amusing tone and sense of humor}

Scholarly papers are not meant to amuse and humor the readers; they are written to educate, to reveal facts, to feed the intellect. Other than this, these types of papers no longer concern themselves with, especially if it has to do with entertaining readers and making them happy.

But then again, the student's paper under consideration violates this rule in academic writing. Using a conversational language, it readily assumes an amusing tone ornamented with a sense of humor. Notice this passage, for instance:

You think Twilight would exist if the French king hadn't been beheaded, and the English Hadn't built factories? Or do you really think that Man Caloy would raise a pig if it weren't for the assassination of Benigno Aquino Jr? Not so, say the Marxists.

The humor here is that, the student-writer resorts to mentioning big historical personages when in fact he is just trying to argue on something trivial. Apparently, this is for emphasis, but when one is arguing the case of a pig yet the comparisons involve kings and would-have-been presidents, that makes it, to some people, quite funny and exaggerated, which is only tolerable in feature writing or creative nonfiction, never in technical writing. But notice how interesting the text gets as a result-it could kick boredom away.

\subsection{Engaging the readers}

Research papers hardly engage the readers in transacting with the texts. If they do, it is usually in a formal and serious manner, using general statements for the general reading audience. But notice the way the student paper writer addresses the readers:

Simple as this may seem, Marxists will tell you it's totally deep when you get into it. For example: ever hear of a little thing called the realist novel? Marxists are here to tell you that it's totally a bourgeois genre.

These lines suggest the style is one of feature for it reveals a clear voice, a tendency to show rather than tell, a dramatic effect, and a conversational approach. Most notably, it addresses the reader as if in a face-to-face manner, like the latter is but a guy next door told about the current intrigues of the day. A reader here cannot help but feel the presence of the writer, hear the latter's convincing voice, and be drawn helplessly to the writer's ideas. 
That means, according to Marxists, that every time you write, you're advancing your cause. What cause do you think does Tipa-Manila advance?

Again, in the lines above, the student-writer addresses the reader as you, which is a clear manifestation of engaging the latter. Furthermore, the writer even goes beyond mere addressinghe urges the reader to answer a question in the next sentence, which is a more compelling form of reader engagement. With this question, the reader is prompted to think, to come up with an answer, and to analyze the story with the student-critic, thus participating in the critical treatment of the text. This idea of actively engaging readers, of getting them involved, is a common style in feature writing as can be sampled by articles in commercial magazines which, as common knowledge has it, enjoy massive readerships due to their feature-penned articles.

\subsection{Intentional impairment of sentence structures}

One attribute of feature articles is that, they seem to be liberated from grammar rules and linguistic structures. This means that they can violate these rules at will, that they are not obliged to follow them, equipped as they are with the so-called poetic license. While academic writing does the opposite, feature style frequents its use, as exemplified by the student's work under scrutiny.

Say what? Well, Marxists think they have the answer to pretty much any question you might have including questions pertaining to literary works. They even think they can predict the future. So what's this all about? Can you really predict the future using Tipa-Manila? Is it mind reading? Sorcery? Mumbo-jumbo?

The above paragraph contains grammatical and structural violations. The first sentence alone, a question, already ignores the rule that requires all sentences to be complete, with subject and predicate. No doubt it is incomplete. And surely, it cannot stand alone as a meaningful statement. It has to rely on context for meaning. This violation is even repeated toward the end with those words 'sorcery' and 'mumbo-jumbo,' which technically appear as sentences for being ended with question marks. But they are not, substantially, and rule-wise.

Yet, as part of a feature article, the paragraph above could be acceptable. Those incomplete sentences even add beauty of expression. They enhance the mood, the tone, the style. They make the pace more leisurely, the utterance conversational and entertaining. All this characterize the way feature articles are penned; they may not dwell on serious matters, but the interest they create and their ability to attract readers are so great.

\subsection{Laden with descriptive words and phrases}

The presence of numerous descriptive words, phrases, and clauses in a text is an indication that the same is a feature article. These things abound in the student's, supposedly, academic paper. As a result of having these in abundance, his 'critique' is able to yield a clear voice, vivid local color, expressive emotions, concrete details, scenic environment, enhanced characterization, and interesting focus. Take, for example, the simple line below:

From this we can safely say that the work represents the lower class and their simple, ordinary, yet eventful lives.

Notice how he made use of those adjectives and all, appropriately. These are the kinds of words needed in penning feature write-ups. He simply utilized them. But of course, this could not have been possible were it not for his good command of the language-in writing, that is.

Combined with this is his knowledge and skill in feature writing, which he must have had, otherwise he would not be able to write the way he did. More of these descriptive words can be had in the following lines:

Tipa-Manila somehow proves to be an accurate, humorous, and awesome reflection of the real world setting in the rural areas of Leyte and Samar.

According to Marxists, every story tells us something about the world-and about which side the author is on. The goal is to figure out what that is. And thanks to Marx, we can make some pretty good guesses before we even open a book.

Indeed, there are many ways and styles of writing. The student concerned, perhaps from an 
inborn talent, happens to know how to write one of them-the feature style. His only mistake was his resort to use this style for a paper that requires another technique, which is exactly the opposite. But again, rather than utterly reject his output, this study resolved to determine its wisdom.

\section{Conclusion}

After subjecting the case material to analysis, this paper concludes that although scholarly and academic papers require formal style and strict adherence to rules, they can after all be written using the feature writing techniques. It is further concluded that, besides this possibility, the use of feature style is advantageous as it makes the formal papers fun to read, interesting enough, and entertaining indeed. Educational institutions, then, and the academic community in general, may now consider allowing the use of feature style, not only for ease of reading, but also to ensure wider readership of research and technical papers. Such permission would usher in a breakthrough which, although a little deviant from a prescribed writing tradition, could open up new possibilities on how serious and more relevant ideas in life ought to be presented in a simpler and appealing manner.

\section{References}

Hyland, K. (2004). Disciplinary Discourses, Michigan Classics Ed.: Social Interactions in Academic Writing. University of Michigan Press.

Boyd, A. (2001). Broadcast Journalism: Techniques of Radio and Television News. Oxford: Focal.

Clark, R. (1997). Principles and practice of CLA in the classroom (in Fairclough, N. Ed.) Critical Language Awareness. London: Longman.

Dovey, J. (2000). Freakshow: First Person Media and Factual Television. London: Pluto.

Fowler, R. (1991) Language in the News: Discourse and Ideology in the Press. London: Routledge.

Gutkind, L. (1994). What's in the Name-And What's Not? Creative Nonfiction, 1(1). Retrieved 24 April 2017 from https://www.creativenonfiction.org/issue/1

Harcup, T. (2009). Journalism Principles and Practice $2^{\text {nd }}$. Ed. Thousand Oaks, California: SAGE Publication Inc.

Ivanic, R. (1998). Writing and identity: The discoursal construction of identity in academic writing. Amsterdam: John Benjamins.

Roberts, E. V. (2003). Writing About Literature (10 $10^{\text {th }}$ Ed.) Prentice Hall: New Jersey.

Pennycook, A. (1997). Vulgar pragmatism, critical pragmatism, and EAP. English for Specific Purposes, 16(4), Retrieved 1 December 2007 from www.sciencedirect.com 